Ерохин Василий Леонидович

кандидат экономических наук, доцент Института экономики и менеджмента Харбинского инженерного университета

\section{ЭКОНОМИЧЕСКИЕ АСПЕКТЫ ПРОДОВОЛЬСТВЕННОЙ И ПИЩЕВОЙ БЕЗОПАСНОСТИ В ТЕРРИТОРИЯХ АРКТИЧЕСКОЙ ЗОНЫ РОССИИ [1]}

\section{Аннотация:}

В Арктике аспекты продовольственной и пищевой безопасности включают в себя различные факторы природного, экономического, социального и культурного характера. Сложность таких взаимосвязей возрастает с развитием экономической деятельности в регионе, усилением антропогенного влияния на окружающую среду, прогрессирующими климатическими изменениями и меняющимся характером питания. На примере территорий Арктической зоны России в статье концептуализирован подход к оценке уровня продовольственной и пищевой безопасности с дифференциацией экономических факторов, оказывающих влияние на безопасность в территориях с различными типами социально-экономического развития, экологиче ской ситуации и характера питания. В периоде 1996-2016 г2. выявлены благоприятные и негативные факторы взаимосвязи экономических параметров питания и здоровья отдельно для восьми территорий Российской Арктики. На основе открытых взаимосвязей предложены меры по обеспечению продовольственной безопасности, усилению положительных и снижению отрицательных эффектов для здоровья населения.

Ключевые слова:

Российская Арктика, коренные народы Севера, продовольственная безопасность, пищевая безопасность, сельская местность.
Erokhin Vasily Leonidovich

PhD in Economics, Associate Professor, School of Economics and Management, Harbin Engineering University

\section{ECONOMIC ASPECTS OF FOOD AND NUTRITION SECURITY IN THE TERRITORIES OF THE RUSSIAN ARCTIC [1]}

Summary:

In the Arctic, the issue of food and nutrition security (FNS) brings together concerns over a range of environmental, economic, social, and cultural changes. The complexity of the interrelationships emerges with a growing scale of economic activity, strengthening of human pressure on the environment, progressing climate change, and transforming food consumption patterns. In the case of Russia's Arctic territories, the paper aims to conceptualize an approach to assessing the FNS with the differentiation of economic factors influencing food security of people living in various environments and consuming various types of food. In the period of 1996-2016, the study has identified favorable and negative FNS-health economic interrelationships separately for eight territories of the Russian Arctic zone. Based on the revealed correlations, the per pillar policy interventions have been proposed to ensure food security and promote the positive factors and diminish the adverse impacts of the negative ones on selected health parameters.

Keywords

Russian Arctic, indigenous peoples of the North, food security, nutrition security, rural area.

В суровых условиях Арктики важнейшими условиями выживания коренного населения исторически являлись охота и рыболовство. В последнее время, однако, интенсификация экономического освоения северных территорий привела к значительному росту численности населения, главным образом городского, антропогенной нагрузке на окружающую среду и соответствующему обострению проблем продовольственной и пищевой безопасности. Данная проблематика обсуждается в современной научной литературе в трех основных направлениях: загрязнение традиционных источников пищи (пастбища и вода), изменения климата и ухудшение здоровья населения (как коренного, так и городского) [2].

До недавнего времени большинство исследований в сфере продовольственной безопасности в Арктике фокусировались главным образом на малых и территориально удаленных сообществах коренных жителей Севера, однако подходы к оценке уровня безопасности существенно разнились ввиду различий в трактовках самого термина [3]. Так, Т. Гао [4] и А. Иволга [5] акцентировали внимание на устойчивом развитии сельских территорий Севера как одном из решений данной проблемы; А.А. Ильинова и Д.М. Дмитриева [6] рассматривали экологические аспекты устойчивого развития; В.А. Забродин и К.А. Лайшев [7] проводили анализ состояния различных секторов сельскохозяйственного производства. В.А. Иванов и Е.В. Иванова [8] и Т. Хияма и Х. Такакура [9] среди угроз безопасности выделяют снижающуюся самодостаточность малых поселений в пище, растущую зависимость от поставок продовольствия извне (часто низкого качества и питательной ценности, но по высоким ценам), а также деградацию водных и биологических ресурсов в большинстве территорий, входящих в Арктическую зону России. На фоне нарастания проблем продовольствен- 
ной безопасности А. Кондрашевым и коллегами [10] отмечается необходимость включения населения северных российских территорий в самообеспечение продовольствием с использованием продукции традиционного природопользования коренных народов.

Имея в виду комплексный характер влияния на продовольственную безопасность различных фракторов природного, экономического, социального и культурного характера, развитие экономической деятельности в Арктике, усиление антропогенного влияния на окружающую среду и меняющийся характер питания населения, автор в статье разрабатывает подход к оценке уровня продовольственной и пищевой безопасности, включающий следующие последовательно реализуемые этапы.

Этап 1. Обоснование набора показателей, позволяющих диффференцировать эфффекты экономических фракторов для продовольственной безопасности в территориях с различными типами социально-экономического развития, экологической ситуации и характера питания. Научный вклад заключается в адаптации подхода Продовольственной и сельскохозяйственной организации ООН, согласно которому состояние безопасности достигается в том случае, когда все люди, проживающие на определенной территории, в любое время имеют фризический, социальный и экономический доступ в достаточном объеме к безопасным и качественным продуктам питания [11]. Предлагаемые автором показатели для оценки продовольственной безопасности на Севере разделены на три группы и характеризуют соответственно наличие продовольствия, его экономическую доступность для населения и стабильность доступа к нему.

Этап 2. Разработка шкалы оценки предложенных показателей (таблица 1). Предлагаемая автором шкала для оценки уровня продовольственной безопасности отдельных территорий строится на основе нормативов здорового питания Всемирной организации здравоохранения (ВО3), в частности 70,1 кг/год мяса, 359,9 кг/год молока, 140,3 кг/год овощей, 120,5 кг/год хлеба и 8,4 кг/год рыбы и морепродуктов [12]. Для оценки показателей доступности и стабильности, а также доли традиционных продуктов в рационе использованы данные Федеральной службы государственной статистики РФ, целевые показатели государственной программы «Социально-экономическое развитие Арктической зоны Российской Федерации», а также рекомендации экспертов [13]. Достижение уровня безопасности отмечается баллом 1 (100 \% от норматива). Значение ниже $90 \%$ норматива признается угрозой безопасности (0 баллов), а значение выше $110 \%$ норматива - высоким уровнем безопасности (2 балла).

Таблица 1 - Система показателей продовольственной безопасности для применения в арктических территориях

\begin{tabular}{|c|c|c|c|c|c|}
\hline \multirow{2}{*}{ Измерение } & \multirow{2}{*}{ Показатель } & \multirow{2}{*}{$\begin{array}{c}\text { Единица } \\
\text { измерения }\end{array}$} & \multicolumn{3}{|c|}{ Шкала } \\
\hline & & & 0 & 1 & 2 \\
\hline \multirow{6}{*}{ Наличие } & Потребление мяса & кг/год & $<63$ & $63-77$ & $>77$ \\
\hline & Потребление молока & кг/год & $<324$ & $324-396$ & $>396$ \\
\hline & Потребление овощей & кг/год & $<133$ & $133-147$ & $>147$ \\
\hline & Потребление хлеба и хлебопродуктов & кг/год & $<114$ & $114-126$ & $>126$ \\
\hline & Потребление рыбы и морепродуктов & кг/год & $<7,5$ & $7,5-9,2$ & $>9,2$ \\
\hline & Доля традиционных продуктов в рационе & $\%$ & $<50$ & - & $>50$ \\
\hline \multirow{3}{*}{ Доступность } & Доля расходов на питание в общей структуре расходов & $\%$ & $>34$ & $28-34$ & $<28$ \\
\hline & $\begin{array}{l}\text { Доля населения с доходами ниже прожиточного } \\
\text { минимума }\end{array}$ & $\%$ & $>13$ & $11-13$ & $<11$ \\
\hline & $\begin{array}{l}\text { Доля домохозяйств, в которых имеются охотники, } \\
\text { рыбаки, оленеводы }\end{array}$ & $\%$ & $<50$ & - & $>50$ \\
\hline \multirow{3}{*}{ Стабильность } & $\begin{array}{l}\text { Число дней в году, когда доставка продовольствия } \\
\text { невозможна в связи с погодными условиями }\end{array}$ & дней/год & $>60$ & $30-60$ & $<30$ \\
\hline & Наличие программ безопасного питания & количество & 0 & - & $\geq 1$ \\
\hline & Наличие программ продовольственной помощи & количество & 0 & - & $\geq 1$ \\
\hline
\end{tabular}

Этап 3. Расчет суммарных баллов по каждой из групп показателей и сведение их в итоговую таблицу для определения уровня безопасности как по группе, так и в целом для территории (таблица 2). Выделяются четыре уровня продовольственной безопасности: критически низкая (итоговые значения показателей от 0 до минимально возможной суммы баллов по каждой группе), угроза (показатели в диапазоне между минимально возможной суммой хотя бы по одной из групп и средним значением по группе), безопасность (показатели в диапазоне от среднего значения по группе до максимально возможного хотя бы по одной из групп), высокая безопасность (максимально возможные значения по каждой группе). 
Таблица 2 - Уровни продовольственной безопасности

\begin{tabular}{|l|c|c|c|c|}
\hline \multirow{2}{*}{ Измерение } & \multicolumn{3}{|c|}{ Уровень продовольственной безопасности } \\
\cline { 2 - 5 } & $\begin{array}{c}\text { Критически низкая } \\
\text { безопасность }\end{array}$ & $\begin{array}{c}\text { Угроза } \\
\text { безопасности }\end{array}$ & Безопасность & $\begin{array}{c}\text { Высокая } \\
\text { безопасность }\end{array}$ \\
\hline Наличие & $0,0-2,9$ & $3,0-5,9$ & $6,0-9,9$ & $10,0-12,0$ \\
\hline Доступность & $0,0-0,9$ & $1,0-2,9$ & $3,0-4,9$ & $5,0-6,0$ \\
\hline Стабильность & $0,0-1,9$ & $2,0-3,9$ & $4,0-5,9$ & 6,0 \\
\hline Всего & $0,0-5,9$ & $6,0-12,9$ & $13,0-20,9$ & $21,0-24,0$ \\
\hline
\end{tabular}

Данная шкала применена к территориям, входящим в Арктическую зону России. В целях учета разнообразия типов питания, влияния антропогенного фактора и экологической ситуации на уровень продовольственной безопасности территории были условно разделены на четыре типа:

- тип 1: преимущественно городские агломерации с высокой долей привозных продуктов в рационе (Мурманская и Архангельская области, Республика Коми);

- тип 2: преимущественно индустриализированные территории с высоким уровнем загрязнения окружающей среды (Ямало-Ненецкий автономный округ, Красноярский край);

- тип 3: территории с развитым оленеводством и преобладанием мяса в рационе коренных жителей (Республика Саха (Якутия));

- тип 4: прибрежные территории с преобладанием рыбы в рационе коренных жителей (Hенецкий и Чукотский автономные округа).

Проведенное исследование показало, что в большинстве своем северные территории России не достигают уровня продовольственной безопасности ни по одному из выделенных измерений (таблица 3). Исключением является Ямало-Ненецкий автономный округ с наивысшим среди исследованных регионов уровнем дохода на душу населения и наименьшей долей населения за чертой бедности.

В территориях типа 1 преобладает так называемый «западный» тип питания с высокой долей привозных продуктов в рационе и, соответственно, низким потреблением традиционной пищи. Вследствие экономических проблем (доля населения с доходами ниже прожиточного минимума в 2016 г. составляла 16,7 \% в Республике Коми, 14,3 \% в Архангельской области и 13,0 \% в Мурманской области) во всех территориях типа 1 регистрируется недопотребление мяса, молока и овощей.

Регионы типа 2 характеризуются крайне неблагоприятными экологическими условиями, что оказывает негативное влияние на качество источников традиционной пищи - пастбищ оленей, почвы, водных ресурсов. В таких территориях повышение качества питания возможно за счет завоза продовольствия из других регионов, однако экономическая доступность такого рода продуктов относительно высока только в Ямало-Ненецком автономном округе, где люди могут позволить покупку привозных продуктов питания должного качества, в том числе молочных продуктов, овощей и фруктов. В северных же частях Красноярского края доля населения с доходами ниже прожиточного минимума одна из самых высоких в Российской Арктике - 18,4 \% в 2016 г. При снижении покупательной способности рацион питания смещается от мясных продуктов в сторону мучных и макаронных изделий и низкокачественных пищевых субстанций.

В регионах типов 3 и 4 рационы питания содержат большую долю традиционных для этих территорий продуктов - оленины, рыбы и морепродуктов. Для Республики Саха (Якутия) характерен самый высокий уровень потребления мяса на душу населения среди северных территорий России. Обеспечению продовольственной безопасности, однако, угрожают удаленность и низкая транспортная доступность большинства территорий республики. Рационы питания оленеводов содержат крайне мало овощей и хлебопродуктов, а также молока. Поскольку покупательная способность населения низкая, большинство жителей вынуждены заниматься традиционными видами промысла. Подобно Якутии, на Чукотке и в Ненецком автономном округе высокий уровень потребления традиционных продуктов - рыбы и морепродуктов. Более чем в 80 \% домохозяйств на Чукотке и в $65 \%$ домохозяйств в Ненецком автономном округе люди занимаются охотой и рыболовством. Несмотря на традиционные рационы питания, на Чукотке крайне остра проблема недопотребления многих важных для здоровья продуктов, таких как овощи и мясо. Из-за высокой стоимости доставки экономическая доступность продуктов значительно ниже по сравнению с другими регионами. Привозная продукция, как правило, низкого качества, замороженная, с высоким содержанием консервантов и пищевых добавок для увеличения срока годности.

Разнообразие фракторов, влияющих на питание в Арктике, должно быть учтено при составлении программ развития продовольственной безопасности северных территорий. По результатам проведенного исследования автором разработаны перспективные меры повышения уровня продовольственной и пищевой безопасности населения Российского Севера, которые учитывают различия территорий, рационов питания, целевых групп потребителей и ситуацию по выделенным автором показателям и обобщенным группам параметров продовольственной безопасности (таблица 4). 


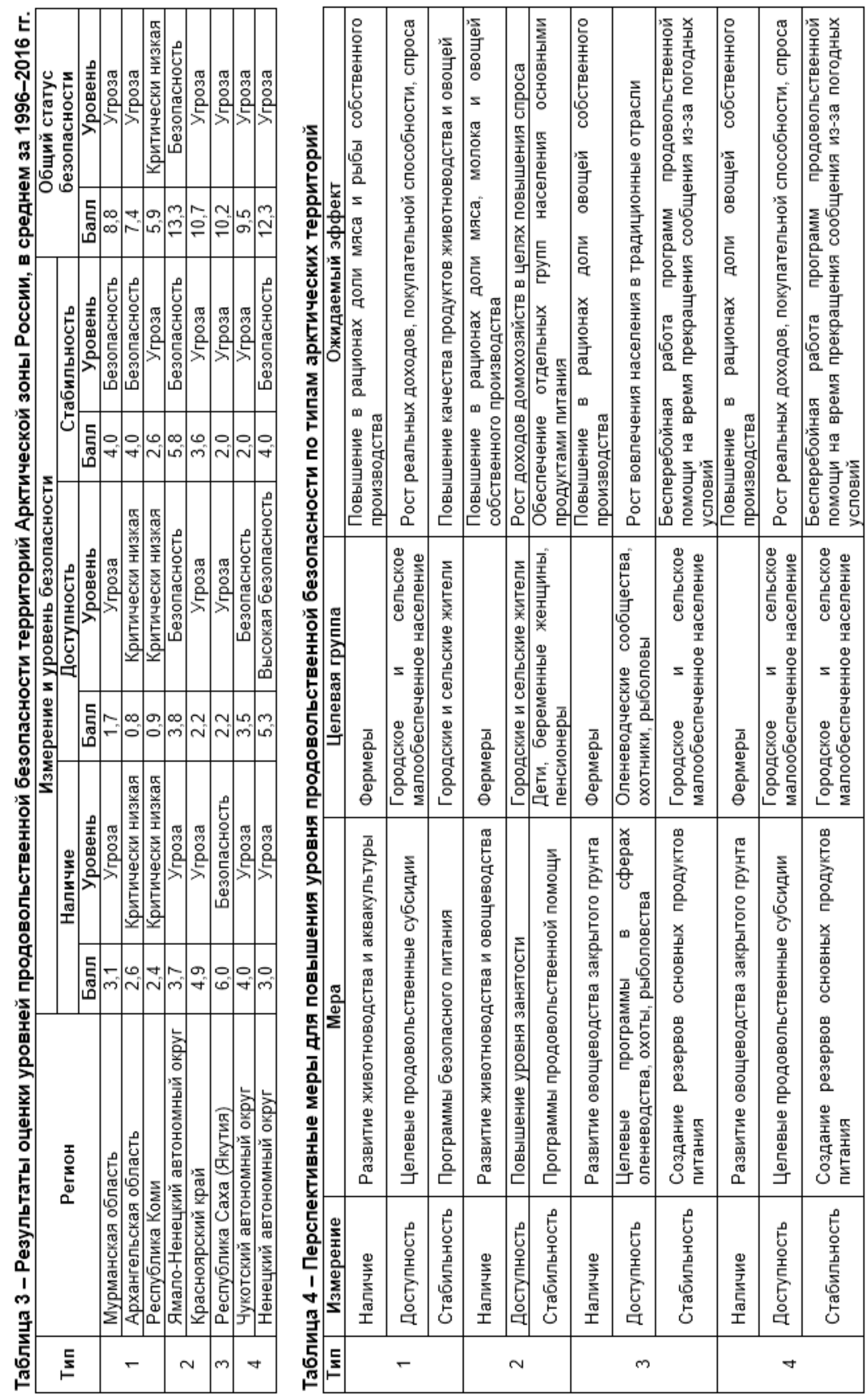


Увеличение потребления основных продуктов питания на душу населения позитивно влияет на продовольственную безопасность во всех типах территорий Российской Арктики, в связи с чем соответствующие меры должны быть направлены на обеспечение как физического наличия, так и экономической доступности таких продуктов на рынке. Поскольку значительная часть населения российских арктических территорий имеет доходы не выше прожиточного минимума, увеличение завоза продовольствия из других регионов с включением транспортных издержек в цену только снизит его экономическую доступность. Одним из решений может стать развитие собственных производств, главным образом животноводства, аквакультуры и овощеводства закрытого грунта. Повышению экономической доступности продовольствия также могут способствовать целевые программы продовольственной помощи и создания резервов на случай прекращения сообщения с центральными регионами страны в связи с погодными условиями. Такие программы особенно актуальны для Чукотки, Якутии, северных территорий Красноярского края и Ямало-Ненецкого автономного округа. Одновременно необходимо повышать качество потребляемых продуктов питания, в перспективе - через программы безопасного питания.

Разработанный подход к оценке уровня продовольственной безопасности территории по ряду критериев и измерений может быть адаптирован и к другим регионам и странам. Его преимущество состоит в том, что на основе балльной системы оценки представляется возможным сделать сравнимыми между собой различные международные и национальные показатели продовольственной безопасности, объединить их в унифицированную систему и тем самым применить к различным условиям северных территорий России и других арктических государств.

\section{Ссылки и примечания:}

1. Настоящее исследование выполнено в рамках проекта HEUCFJ170901.

2. Гао Т., Ерохин В.Л., Иволга А.Г. Политика Китая в сфере обеспечения продовольственной безопасности: современные вызовы // Вестник АПК Ставрополья. 2018. № 1 (29). С. 111-116 ; Лысак М.А. Продовольственная проблема и пути ее решения в мире // Фундаментальные исследования. 2013. № 10-7. С. 1545-1549 ; Таранов П.М., Панасюк А.С. Российская агропродовольственная система в контексте конкурентоспособности и продовольственной безопасности // Экономика сельскохозяйственных и перерабатывающих предприятий. 2011. № 10. С. 20-23.

3. Троцук И.В., Никулин А.М., Вегрен С. Трактовки и способы измерения продовольственной безопасности в современной России: дискурсивные и реальные противоречия // Мир России. 2018. Т. 27, № 1. С. 34-64. https://doi.org/10.17323/1811-038x-2018-27-1-34-64.

4. Gao T. Food Security and Rural Development on Emerging Markets of Northeast Asia: Cases of Chinese North and Russian Far East // Establishing Food Security and Alternatives to International Trade in Emerging Economies / ed. by V. Erokhin. Hershey, PA, 2017. P. 155-176. https://doi.org/10.4018/978-1-5225-2733-6.ch008.

5. Ivolga A. Overview of Contemporary Issues of Sustainable Rural Development in Russia in Terms of Existing Differences between Regions // Economics of Agriculture. 2014. No. 2. P. 331-345. https://doi.org/10.5937/ekopolj1402331i.

6. Ilinova A., Dmitrieva D. Sustainable Development of the Arctic Zone of the Russian Federation: Ecological Aspect // Biosciences Biotechnology Research Asia. 2016. Vol. 13, no. 4. P. 2101-2106. https://doi.org/10.13005/bbra/2370.

7. Лайшев К.А., Забродин В.А. Продовольственная безопасность - основа сохранения и устойчивого развития Арктики // Российская Арктика - территория права : альманах. М. ; Салехард, 2017. С. 246-252.

8. Иванов В.А., Иванова Е.В. Арктическая специфика продовольственного обеспечения и развития сельского хозяйства европейского северо-востока России // Арктика: экология и экономика. 2017. № 2 (26). С. 117-130. https://doi.org/10.25283/2223-4594-2017-2-117-130.

9. Hiyama T., Takakura H. Global Warming and Human-Nature Dimension in Northern Eurasia. Singapore, 2018.235 p. https://doi.org/10.1007/978-981-10-4648-3.

10. The Arctic States' Strategies and the Northern Regions' Food Security / A.O. Kondrashev, M.E. Nikitenko, S.A. Trofimova, I.B. Trofimova, L.G. Gotsko // Економічний часопис-XXI. 2016. №. 162 (11-12). P. 32-37. https://doi.org/10.21003/ea.V162-07.

11. Клещевский Ю.Н., Казанцева Е.Г. Оценка уровня продовольственной безопасности страны // Техника и технология пищевых производств. 2014. № 3 (34). С. 163-169.

12. Щетинина И.В. О продовольственной безопасности России // ЭКО. 2015. № 1 (487). С. 124-138.

13. Indicators of Food and Water Security in an Arctic Health Context - Results from an International Workshop Discussion / L.M. Nilsson, J. Berner, A.A. Dudarev, G. Mulvad, J.Ø. Odland, A. Parkinson, A. Rautio, C. Tikhonov, B. Evengård // International Journal of Circumpolar Health. 2013. Vol. 72, no. 1. P. 21530. https://doi.org/10.3402/ijch.v72i0.21530.

\section{References:}

Gao, T 2017, 'Food Security and Rural Development on Emerging Markets of Northeast Asia: Cases of Chinese North and Russian Far East', in V Erokhin (ed.), Establishing Food Security and Alternatives to International Trade in Emerging Economies, Hershey, PA, pp. 155-176, https://doi.org/10.4018/978-1-5225-2733-6.ch008.

Gao, T, Erokhin, VL \& Ivolga, AG 2018, 'China's Policy in the Field of Food Security: Modern Challenges', Vestnik APK Stavropol'ya, no. 1 (29), pp. 111-116, (in Russian).

Hiyama, T \& Takakura, H 2018, Global Dimension in Northern Eurasia, Singapore, 235 p., https://doi.org/10.1007/978-98110-4648-3.

Ilinova, A \& Dmitrieva, D 2016, 'Sustainable Development of the Russian Federation: Ecological Aspect', Biosciences Biotechnology Research Asia, vol. 13, no. 4, pp. 2101-2106, https://doi.org/10.13005/bbra/2370.

Ivanov, VA \& Ivanova, EV 2017, 'Arctic Specificity of Food Supply and Agricultural Development in the European Northeast of Russia', Arktika: ekologiya i ekonomika, no. 2 (26), pp. 117-130, https://doi.org/10.25283/2223-4594-2017-2-117-130, (in Russian). Ivolga, A 2014, 'Overview of Contemporary Issues of Sustainable Rural Development in Russia in Terms of Existing Differences between Regions', Economics of Agriculture, no. 2, pp. 331-345, https://doi.org/10.5937/ekopolj1402331i. 
Kleschevsky, YuN \& Kazantseva, EG 2014, 'Assessment of the Level of Food Security of the Country', Tekhnika $i$ tekhnologiya pishchevykh proizvodstv, no. 3 (34), pp. 163-169, (in Russian).

Kondrashev, AO, Nikitenko, ME, Trofimova, SA, Trofimova, IB \& Gotsko, LG 2016, 'The Arctic States' Strategies and the Northern Regions' Food Security', Yekonomichniy chasopis-XXI, no. 162 (11-12), pp. 32-37, https://doi.org/10.21003/ea.V162-07.

Layshev, KA \& Zabrodin, VA 2017, 'Food Security is the Basis for the Preservation and Sustainable Development of the Arctic', Rossiyskaya Arktika - territoriya prava: al'manakh, Moscow, Salekhard, pp. 246-252, (in Russian).

Lysak, MA 2013, 'Food Problem and Ways to Solve It in the World', Fundamental'nyye issledovaniya, no. 10-7, pp. 15451549, (in Russian).

Nilsson, LM, Berner, J, Dudarev, AA, Mulvad, G, Odland, JØ, Parkinson, A, Rautio, A, Tikhonov, C \& Evengård, B 2013, 'Results of the International Workshop Discussion', International Journal of Circumpolar Health, vol. 72, no. 1, pp. 21530, https://doi.org/10.3402/ijch.v72i0.21530.

Shchetinina, IV 2015, 'On Food Security of Russia', EKO, no. 1 (487), pp. 124-138, (in Russian).

Taranov, PM \& Panasyuk, AS 2011, 'Russian Agri-Food System in the Context of Competitiveness and Food Security', Ekonomika sel'skokhozyaystvennykh i pererabatyvayushchikh predpriyatiy, no. 10, pp. 20-23, (in Russian).

Trotsuk, IV, Nikulin, AM \& Vegren, S 2018, 'Interpretations and Ways to Measure Food Security in Modern Russia: Discursive and Real Contradictions', Mir Rossii, vol. 27, no. 1, pp. 34-64, https://doi.org/10.17323/1811-038x-2018-27-1-34-64, (in Russian). 